\title{
DESAFIOS DA EDUCAÇÃO ESCOLAR INDÍGENA: EPISTEMOLOGIAS E FILOSOFIAS
}

\author{
CHALLENGES OF INDIGENOUS SCHOOL EDUCATION: \\ EPISTEMOLOGIES AND PHILOSOPHIES
}

Eduardo Barbosa Vergolino ${ }^{1}$

\begin{abstract}
RESUMO: Os desafios da educação escolar indígena são apresentados por muitos estudiosos, pesquisadores e indígenas como uma das inúmeras fontes de desigualdade social decorrente de um processo histórico e político-social que vem multiplicando uma série de barreiras nas quais a educação escolar indígena acaba por enfrentar. A educação escolar indígena além dos inúmeros desafios de adaptação, criação e fomento interno defrontam-se em seus inúmeros espaços físicos e tecidos sociais com uma série de provocações quanto as utilizações de suas Epistemologias e Filosofias próprias. O presente trabalho tem como principal linha de análise e discussão uma abordagem crítica aos conceitos de Epistemologia e Filosofia que para com os Povos Indígenas de modo geral, lhes são muitas vezes tolhidas a possibilidade de utilização de tais percepções do conhecimento. Mais ainda, quais os desafios de uma educação escolar indígena que deve dialogar com epistemologias e filosofias distintas dentro de um mesmo espaço escolar?
\end{abstract}

Palavras-Chave: Descolonização; Conhecimento indígena; Pedagogia.

\begin{abstract}
The challenges of indigenous school education are presented by many scholars, researchers and indigenous people as one of the many sources of social inequality resulting from a historical and political-social process that has been multiplying a series of barriers in which indigenous school education ends up facing. In addition to the innumerable challenges of adaptation, creation and internal development, indigenous schooling faces in its many physical spaces and social tissues a series of provocations regarding the uses of its own Epistemologies and Philosophies. The present work has as its main line of analysis and discussion a critical approach to the concepts of Epistemology and Philosophy that for Indigenous Peoples in general, they are often denied the possibility of using such perceptions of knowledge. Moreover, what are the challenges of an indigenous school education that must dialogue with different epistemologies and philosophies within the same school space?
\end{abstract}

Key words: Decolonization; Indigenous knowledge; Pedagogy.

A diversidade de Povos Indígenas no Brasil e de suas especificidades locais e regionais acaba por promover a necessidade de um debate para além dos desafios específicos de cada povo.

\footnotetext{
${ }^{1}$ Professor de Filosofia do IF-Sertão-PE, Campus Floresta. Doutorando em Estudos Nativos na Universidade de Manitoba - Canadá.
} 
A epistemologia deixa de ser um campo singular para na multiplicidade das vozes buscar um conhecimento que não mais tem o direito de se colocar como referência, mas sim, um universo conceitual que deve ser aberto para diferentes formas de relações na formação do conhecimento. A epistemologia como forma de estudar a formação do conhecimento humano e possuindo na educação escolar uma de suas mais importantes ferramentas de disseminação do conhecimento, acaba por inviabilizar o reconhecimento de epistemologias diferentes da dominante.

Não se trata de argumentar pela simples relação entre grupos, práticas ou conhecimentos
culturais, ou pela inclusão dos tradicionalmente excluídos dentro das estruturas
(educativas, disciplinares ou de pensamento) existentes, ou pela criação de programas
"especiais" para eles, atendendo a demandas pontuais, mas que permitem que a educação
"normal" e "universal" siga perpetuando práticas e pensamentos racializados e
excludentes. (PALADINO e CZARNY, 2012, p. 22)

O conhecimento abordado em sala de aula no caso específico das escolas indígenas tem como um de seus maiores desafios a interlocução entre diferentes epistemologias. Diferentes formas de conhecer o mundo e de produzir conhecimento buscam uma sinergia dentro da sala de aula que muitas vezes esbarra nas complexidades intrínsecas as peculiaridades e especificidades de cada povo. No que tange as formas de pensar e construir conhecimento dentro e fora dos povos indígenas acabam por recair nas práticas e pedagogias abordadas em salas de aula. Eis que os desafios da educação escolar indígena não se restringem apenas as formas ou teorias pedagógicas abordadas, mas também a forma como se pensa a educação escolar como um todo. Desde a organização pedagógica até as epistemologias e filosofias que fundamentam a educação escolar nas comunidades e povos indígenas o pensar a educação deve passar por uma análise e discussão com a participação dos principais afetados.

O eixo norteador do debate da educação escolar indígena deve buscar se pautar em uma experiência descolonizadora, reflexiva e crítica visando uma inclusão de conceitos e aspectos essenciais e específicos de cada povo indígena. Segundo Mitchell, Thomas e Smith:

\footnotetext{
Perguntas críticas devem ser feitas e histórias alternativas contadas sobre colonização. As narrativas da comunidade indígena cruzam e contradizem os relatos dominantes do colonialismo dos colonos. As narrativas indígenas revelam a existência de muitas culturas diversas e ricas, com economias sofisticadas, estruturas de governança, leis, educação, saúde, bem-estar social, diplomacia e práticas de bem-estar infantil antes do contato e do estabelecimento. (2018, p. 353).
}

Afirmar que apenas existem filosofias no universo eurocêntrico e o que podemos chamar de um imperialismo filosófico estabelecido pelas forças opressivas da colonização europeia ao dito "Novo Mundo". "Os colonizadores requerem um sistema de pensamento e representação para mascarar seu comportamento opressivo. Em outras palavras, eles exigem uma ideologia para legitimar e consolidar as relações desiguais de poder estabelecidas por todo o processo de 
colonização" (LaRocque, 2010, p. 37). As Américas bem como diversas outras partes terrestres do planeta estavam povoadas com formas de pensar e filosofias, bem como processos educacionais próprios. No entanto, a Filosofia como estudo de um conceito do saber humano baseado no cosmopolitismo elitista europeu acabou por excluir e não reconhecer a legitimidade e a complexidade do conhecimento humano e da formação do mesmo, dentro de comunidades hoje chamadas comunidades Indígenas, ou Povos Indígenas, ou Povo Originários, dentre outras tantas denominações. Aqui, neste trabalho pretendo utilizar a conceituação mais abrangente utilizada por diversos povos e grupos ao redor do mundo que e a utilização do termo Indígena. Para muitos Filósofos, os Povos Indígenas não possuem o que o Ocidente chama de Filosofia. De acordo com Freire, "A educação é para domesticação ou liberdade. Embora seja costumeiramente concebido como um processo de condicionamento, a educação também pode ser um instrumento para o decondicionamento. É necessária uma escolha inicial do educador” (Freire, 1970, p. vi). A Filosofia então parece debruçar-se apenas nos rincões do pensamento humano, advindo de qualquer que seja o centro europeu ou sua ramificação, ou espaço colonizado. A Filosofia oriunda dos homens que habitavam as terras desconhecidas dos europeus eram sumariamente desprezadas e ignoradas, o que atualmente em diversos Povos Indígenas ao redor do mundo se mostra como uma ideia falsa, equivocada e preconceituosa.

Mas aqui iremos tratar da possibilidade de uma interlocução entre a Filosofia da Educação e o conhecimento Tradicional dos Povos Indígenas numa abordagem mais problematizante como forma de pensar uma Filosofia da Educação autônoma e independente advinda do pensamento Indígena. "A educação, nesse contexto, se torna educação pelo bem da vida. A educação é, em sua essência, aprender sobre a vida através da participação e relacionamento na comunidade, incluindo não apenas pessoas, mas plantas, animais e toda a natureza" (AIKENHEAD e MICHELL, 2011) (BATTISTE, 2002) (BERNARDO, 2001) (CAJETE, 1994) (FREIRE, 1970) (HAIG-BROWN, 1995) (KOVACH, 2005) (KOVACH, 2009) (KOVACH, 2010) (KULCHYSKI, 2000) (KUOKKANEN, 2007) (LAROCQUE, 2010) (NEWHOUSE, 2011) (SIMPSON, 2002) (SIMPSON, 2011) (UTTUNEE) (WUT'TUNEE, 2004)(Cajete, 1994, p. 26). Pois, aqui não venho de forma solipsista desenvolver ou defender um cabedal teórico em prol de uma Filosofia da Educação elitista e eurocêntrica, mas sim, problematizar uma possibilidade do Conhecimento Tradicional Indígena de forma tal que seu conjunto de epistemologias e formas de saber seja abraçado pela Filosofia como fonte inspiradora de busca de novos paradigmas conceituais. 
A Filosofia como disciplina deve buscar entender e conhecer os espaços sociais e conceituais de diversos povos sem buscar a implementação de uma estrutura ao universo conceitual diferente do estabelecido pela sociedade tida como convencional. A Filosofia até poucas décadas atrás estava voltada e concentrada em aplicar seus conceitos abstratos e lógico-racionais as diversas formas de pensar como se essas ditas "novas" formas de saber tivessem que se submeter aos modelos já estabelecidos por uma herança aquém de sua existência. "Essa abordagem para entender o mundo e seus habitantes moldou muitas disciplinas acadêmicas. Valores, culturas e espiritualidade são compartimentados e têm pouco significado nesse aspecto científico das visões de mundo eurocanadenses; no entanto, eles têm significado na religião e em outros aspectos não científicos de nossa experiência”. (Wuttunee, 2004, p. 5). A Filosofia e, principalmente, a Filosofia da Educação, devem debruçar-se sobre novas epistemologias e culturas a fim de buscar entender e explorar novos paradigmas conceituais externos ao universo eurocêntrico imperialista. Marie Battiste afirma ser o cognitivismo imperialista:

As políticas de produção e disseminação do conhecimento estão no cerne da questão, pois os estudiosos revelam a maneira culturalmente imperialista e corrompida pela qual o conhecimento acadêmico foi legitimado, produzido, empacotado e disseminado nos currículos e políticas escolares sancionados pelo governo. (Battiste, 2002)

Onde as esferas cognitivas e conceituais dos Povos Indígenas acabam por serem excluídas do universo conceitual da Filosofia tornando o conhecimento tradicional indígena uma esfera cognitiva e epistemológica alheia ao universo filosófico dominante.

Discutir o imperialismo cognitivo imposto pela filosofia eurocêntrica deve ser um papel fundamental no que tange o espectro filosófico da Filosofia da Educação. O processo hoje de decolonização ou descolonização abordado por diversos antropólogos, historiadores e estudiosos das ciências sociais e humanas ainda vagueia tímida nas entranhas do universo filosófico. A Filosofia como disciplina debruçada em conceitos e ontologias oriundas de reinos opressores acaba por não abrir as portas para um universo ontológico e epistemológico dos Povos Indígenas no mundo, e mais especificamente, no Brasil. Apesar do Brasil estar entre os muitos países com grande diversidade de Povos Indígenas, existe ainda um imperialismo cognitivo dos conceitos fundamentais impostos pela herança Europeia em nossa cultura. De fato, podemos perceber este distanciamento e exclusão das filosofias indígenas desde as abordagens dos indígenas nas escolas primárias, até o papel do ensino sobre as culturas Indígenas nos diversos cursos universitários pelo Brasil afora.

A Filosofia como saber teórico deve na prática buscar entender e discutir a pluralidade de conhecimentos sem através de estruturas conceituais pré-estabelecidas impor uma forma de 
pensar. A Filosofia da Educação como disciplina que busca entender a diversidade teórica acerca da formação do conhecimento e do seu processo de ensino-aprendizagem deve olhar para o universo cultural Indígena como um campo de quebra de paradigmas do convencional. A imposição de conceitos ou sistemas advindos de universos alheios aos Povos Indígenas compreende uma ignorância e de tal sorte revela-se como uma forma opressiva e racista de pensar o conhecimento Indígena.

\begin{abstract}
A filosofia do índio baseia-se na percepção de que, na ordem do universo ("a ordem das coisas"), os seres humanos são os últimos. Os índios sabem que suas vidas dependem da vida de outras pessoas no esquema das coisas e, no entanto, a vida do outro não depende da vida dos índios. Eles se sentem humildes quando reconhecem que todas as coisas são interdependentes, mas são as mais dependentes. Todas as outras coisas dentro do universo podem existir sem elas e permanecer em harmonia. Só eles não podem existir sem os outros. (Haig-Brown, 1995, p. 4).
\end{abstract}

A educação Indígena seja ela formal ou informal (dentro ou fora da escola) apresentase como uma alternativa muito a frente ao nosso tempo. Uma educação baseada na individualidade do sujeito e nas suas habilidades pessoais sem imposição de modelos alheios a comunidade, uma educação orientada à sustentabilidade social e ambiental, uma educação na qual a diversidade de elementos integradores do conhecimento está conectada de forma a criar dentro do indivíduo um sentido de completude humana e social.

O conhecimento tradicional Indígena possui uma estrutura, assim como em diversas culturas, baseada em uma sistematicidade do conhecimento. Entretanto, as esferas conceituais subjetivamente definidas muitas vezes não se aplicam da mesma forma em culturas baseadas em conceitos estáticos e universalizantes. O conhecimento tradicional Indígena mostra-se como um conhecimento que emana das atividades e vivências humanas no mais íntimo das relações humanas com o todo a sua volta. A Filosofia da Educação segundo Bernardo (2001), "A Filosofia da Educação deverá, por conseguinte, produzir uma crítica da razão pedagógica, tarefa propedêutica de qualquer investigação coerente sobre as condições de possibilidade do ato educativo" (p. 208). O autor corrobora o pensamento racionalista moderno no qual a Filosofia da Educação deve primar por um debate racionalista de base Europeia. No entanto, ao pontuar a necessidade de uma autocrítica da Filosofia quanto ao espaço de discussão acerca dos elementos e estruturas educacionais como forma de ressignificar a ideia de educação, o autor prioriza a herança Europeia. A Filosofia da Educação necessita se voltar a novos horizontes e principalmente ao universo do conhecimento Indígena como forma de construir uma autocrítica necessária para o desenvolvimento de novos modelos e estruturas educacionais.

As histórias criam uma epistemologia holística para abordar as naturezas intelectual, espiritual, emocional e física das crianças. Uma estreita afinidade, como um parentesco, foi estabelecida com o meio ambiente. As histórias também ensinaram aspectos da 
ciência ambiental, história, geografia e muito mais. Esperava-se que as crianças participassem de um processo de aprendizado. Eles não receberam uma aula didática e não deveriam escrever respostas para uma lista de perguntas de compreensão sobre as histórias. Histórias ou partes de histórias foram repetidas em diferentes ocasiões e ouvidas várias vezes ao longo da vida. (Newhouse, 2011, p. 165).

A Filosofia da Educação deve debruçar-se sobre o conhecimento e a formação do processo educacional Indígena com fins de aprender como é possível unir a Filosofia da Educação e o Pensamento Tradicional Indígena.

É importante repetir essa ideia central: Os pressupostos de realismo, realismo crítico e positivismo negam a legitimidade do conhecimento indígena como uma maneira fundamental de entender o mundo físico. Essa negação trivializa o conhecimento indígena para o status de tokenismo. A negação compromete as tentativas de complementar uma visão de mundo científica com uma apreciação de uma visão de mundo indígena na ciência escolar. (Aikenhead \& Michell, 2011, p. 61).

O conhecimento tradicional Indígena possui ontologias e epistemologias que não se fundamentam em uma dualidade característica do pensamento racionalista eurocêntrico. $O$ ser não está para o mundo como algo alheio ao universo natural, mas sim, como parte integrante de um todo onde ser e mundo se encaixam em uma única esfera. $\mathrm{O}$ ser pensante está integrado como partícipe de um universo maior. A natureza não se apresenta como algo alheio ao ser, mas como uma parte do ser. Podemos dizer que o processo de significação e/ou ressignificação do ser se dá através de uma união indissolúvel entre ser e natureza. Nesse contexto, a educação Indígena como processo de transmissão do conhecimento se fundamenta em aspectos não reconhecidos pelo universo colonial como integrantes de uma ontologia humana. O poder dos mitos e das histórias possui muitas vezes um local de pouca importância no universo conceitual baseado no racionalismo intelectual eurocêntrico.

A educação indígena e sua expressão em várias culturas ao redor do mundo refletem todos os estágios míticos da consciência humana. Eles formam quadros de referência para perceber toda a evolução da consciência humana. Ao estudar a educação indígena, todo grupo cultural moderno pode explorar a realidade do processo de pensamento mítico por meio de suas manifestações. Isso introduz uma alfabetização mitológica na educação moderna, que é desprovida de tais explorações, exceto no domínio altamente especializado do mitólogo. (Cajete, 1994, p. 136)

De acordo com Gregory Cajete, o conhecimento mítico é fundamental na construção do conhecimento humano a partir da perspectiva Indígena. O conhecimento mítico como forma de expressão humana e de posicionamento do indivíduo no tempo e no espaço transborda o modelo conceitual onto-epistemológico de sociedades europeias. Desta forma, com o posicionamento do indivíduo a partir de um "novo" espectro onto-epistemológico a elaboração de conceitos não pode advir de um pré-estabelecido universo conceitual, mas sim, de uma busca de entendimento e colaboração de construção de uma filosofia da educação que represente e busque 
analisar o conhecimento tradicional indígena a partir do universo indígena, e não de uma aplicação de conceitos alienados, alienantes e alienadores de origem europeia nas formas de pensar indígena.

Concluímos, portanto, que a busca por uma resposta mais crítica quanto a construção de epistemologias e filosofias deve ser repensada nos espaços escolares, principalmente quando houver especificidades mais amplas como no caso das escolas indígenas. O imperialismo cognitivo estabelecido pela forma de pensar dominante já não consegue nem deve se propor a ser a única e exclusiva via de pensar. O conhecimento tradicional indígena reclama para si a possibilidade e a autoridade de com um outro olhar, diferente do eurocêntrico, criar uma forma de entender as epistemologias e filosofias de seus mundos. O universo escolar indígena vem como ferramenta e espaço de inclusão desses conceitos epistemológicos e filosóficos no sentido de que a forma como conhecemos e pensamos o mundo seja reproduzido em salas de aulas de forma plural e diversa.

O pensar e o fazer as escolas indígenas deve ser permeado majoritariamente pela forma de pensar e produzir conhecimento indígena. O imperialismo cognitivo que não aceita o diferente já não responde mais, ou se encaixa nos diálogos do fazer nos espaços escolares. As escolas indígenas possuem o desafio de ao se fazerem espaços de conhecimento não privilegiarem o externo em detrimento do interno. A forma de conhecer indígena e o conhecimento tradicional indígena devem ser o fundamento das escolas indígenas, principalmente no que tange aos métodos de fazer conhecimento. A epistemologia e a filosofia dominante dentro das escolas indígenas devem ser de origem indígena para que o pensar o conhecimento em si dentro da comunidade não se perca.

O conhecimento tradicional indígena com suas epistemologias e filosofias específicas tem como desafio vencer as barreiras da institucionalidade e universalidade do conhecimento nãoindígena. Apesar dos inúmeros desafios, a educação escolar indígena vem se reinventando e construindo saídas para a inclusão de suas demandas apesar da pouca ou quase nenhuma forma de incentivo por parte das instituições, ou mesmo do Estado. A carência de incentivos institucionais visando o melhor desenvolvimento das escolas indígenas perpassa os mais variados segmentos da educação, desde investimentos em prédios e salas de aula, passando por livros e materiais didáticos específicos para cada povo ${ }^{2}$ até o conhecimento a ser ensinado em sala de aula como forma de alienação e reprodução de um sistema opressor e dominante. Portanto, desafios para a educação escolar indígena são muitos e devem ser discutidos e analisados em conjunto com cada povo trabalhando para em suas especificidades buscar soluções que respeitem suas histórias, epistemologias e filosofias.

\footnotetext{
${ }^{2}$ Material didático específico para cada povo continua sendo um desafio.
} 


\section{Obras Citadas}

AIKENHEAD, G.; MICHELL, H. Bridging Cultures: Scientific and Indigenous Ways of Knowing Nature. Toronto: Pearson Canada Inc., 2011.

BATTISTE, M. Indigenous Knowledge and Pedagogy in First Nations Education: A Literature Review with Recommendations. Ottawa: Apamuwek Institute, 2002.

BERNARDO, L. M. O regresso da filosofia da educação: novos desafios para uma velha disciplina. Revista da Faculdade de Ciências Sociais e Humanas, n. n. 14, 2001. 203-210. CAJETE, G. Look to the Mountain: An Ecology of Indigenous Education. [S.1.]: Kivaki Press, 1994.

FREIRE, P. Cultural Action for Freedom. [S.l.]: Harvard Educational Review, 1970.

HAIG-BROWN, C. Making the Spirit Dance Within: Joe Duqette High School. Toronto: Canadian Education. Association, 1995.

KOVACH, M. Emerging from the Margins: Indigenous Methodologies. In: BROWN, L. A. Research as Resistance: Critical, Indigenous and Anti-Oppressive Approaches. Toronto: Canadian Scholar's Press, 2005. p. 19-36.

KOVACH, M. Indigenous Methodologies: characteristics, conversations, and contexts. Toronto: University of Toronto, 2009.

KOVACH, M. Conversatin Method in Indigenous Research. First People Child \& Family Review, p. 40-48, 2010.

KULCHYSKI, P. Expressions in Canadian Native Studies. Saskatchewan: University of Saskatchewan Extension Press, 2000.

KUOKKANEN, R. Reshaping University: responsability, indigenous epistemes, and the logic of the gift. Vancouver: UBC Press, 2007.

LAROCQUE, E. When the Other is Me: Native Resistance Discourse. Winnipeg: University of Manitoba Press, 2010.

NEWHOUSE, D. R. Hidden in Plain Sight: contributions of Aboriginal Peoples to Canadian Identity and Culture. London: University of Toronto Press, 2011.

PALADINO, M.; CZARNY, G. Povos Indígenas e Escolarização: discussões para se repensar novas epistemes nas sociedades latino-americanas. Rio de Janeiro: Garamond, 2012.

PALADINO, M.; CZARNY, G. Povos Indígenas e Escolarização: discussões para se repensar novas epistemes nas sociedades latino-americanas. Rio de Janeiro: Garamond, 2012.

SIMPSON, L. Indigenous Environmental Education for Cultural Survival. Canadian Journal of Environmental Education, 2002. 13-25. 
SIMPSON, L. Dancing on Our Turtle's Back: Stories of Nishnaabeg Re-creation, Ressurgence and a New Emergence. Winnipeg: ARP Books, 2011.

UT'TUNEE,. [S.l.]: [s.n.].

WUTTUNEE, W. Living Rhythms: lessons in aboriginal economic resilience and vision. London: McGill-Queen's University Press, 2004. 